\title{
Spontaneous splenic rupture following bacterial endocarditis
}

de Silva T, Wickremasuriya PKH, Wettasingha S, Gamage N, Wijenaike K

\section{Introduction}

Spontaneous rupture of the spleen is a rare complication of bacterial endocarditis. Early diagnosis and prompt treatment is vital as resultant haemorrhagic shock is often fatal. We present a case of spontaneous rupture of spleen following enterococcus endocarditis.

\section{Case report}

69-yr-old man presented with a history of low grade fever for two weeks duration. Apart from malaise lethargy and fever he did not have any overt evidence of a focus of infection. Pan systolic mitral regurgitant murmur was found on examination. His white cell count (WCC) was 8100 with low grade anaemia (Haemoglobin $10 \mathrm{~g} / \mathrm{dL}$ ). C reactive protein was 59 and sedimentation rate was not rapid (25/hr). Blood cultures isolated entrococcus feacalis. Echocardiogram revealed an oscillating vegetation on the posterior cusp of the mitral valve. Infective endocarditis was diagnosed and crystalline penicillin and gentamicin were commenced accordingly. After a week of antibiotics at the district general hospital he was transferred to a local hospital for continuation of antibiotics. After 25 days of antibiotics therapy patient was transferred back with acute severe abdominal pain. Systolic blood pressure was $60 \mathrm{~mm} \mathrm{Hg}$. Abdomen was tender. Ultra sound examination revealed a heterogeneously enlarged spleen with a $12.2 \times 3.8 \times 8.6 \mathrm{~cm}$ size peri-splenic haematoma. Moderate to gross amount of blood noted in para-colic gutters.

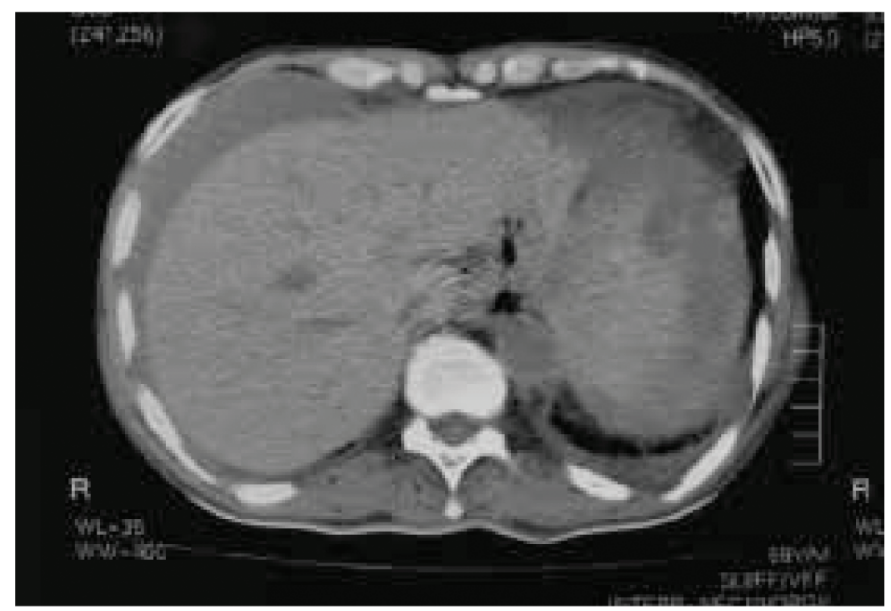

CT scan showing splenic hematoma

General Medical Unit District General Hospital Matara
Haemoglobin was $5.9 \mathrm{~g} / \mathrm{dL}$. Patient required four units of red cell transfusion for initial resuscitation. Once the patient was stable he underwent splenectomy. Ruptured spleen was removed with the hematoma. Post-operatively, the patient received pneumococcal, meningococcal and haemophilus vaccinations and was discharged on life-long penicillin prophylaxis.

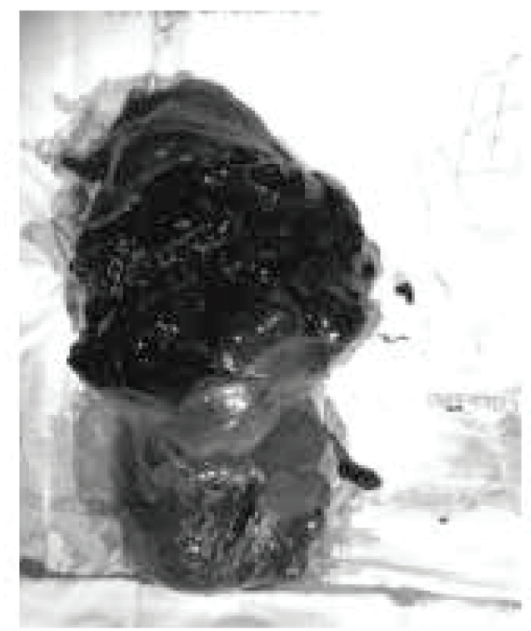

\section{Ruptured spleen}

\section{Discussion}

Spontaneous rupture of the spleen has been reported in association with neoplasm (leukaemia), infections (infectious mononucleosis, endocarditis), anticoagulation and acute and chronic pancreatitis ${ }^{1}$. However there are no comprehensive assessments of incidence rates, causes, specific symptoms, management options in the literature ${ }^{2}$. Patient may not have typical features of an organ rupture, peritonism or left shoulder tip pain. Clinicians should have a high degree of suspicion not to miss this fatal condition. Usually the diagnosis is clinical, confirmed by either computerised tomography (CT) or magnetic resonant imaging. Initial resuscitation may need blood, clotting products and vasopressors as haemorrhagic shock is common.

There are a number of possible mechanisms for splenic rupture in endocarditis. It may occur secondary to simple infarction butalso been reported following splenic abscess formation secondary to septic embolisation. The incidence of splenic abscess 
formation post endocarditis is approximately $5 \%^{3}$. The incidence of splenic embolism is reported as between 5 and $12 \%{ }^{4}$. Our patient's spleen did not show evidence of suppurative necrosis and probably rupture was secondary to an infarction. Study on offending organism and the incidence of embolisation has found an embolisation rate of $26 \%$ for enterococcus endocarditis which is significantly less than staphylococcal aureus endocarditis and similar to streptococcal endocarditis ${ }^{5}$. Mobile and large vegetation has a higher risk of embolisation. Incidence of embolisation becomes less with length of treatment ${ }^{4}$.

Conservative management is unlikely to succeed there should be a low threshold for laparotomy if the patient remains haemodynamically unstable despite resuscitation. Several useful grading systems based on CT or ultrasound findings have been established to guide management decisions. However clinical assessment is vital as delayed splenic rupture requiring surgery may occur in patients whose initial CT shows low-grade splenic injury ${ }^{2}$.

\section{References}

1. Renzulli P, Hostettler A, Schoepfer AM, et al. Systematic review of atraumatic splenic rupture. Br J Surg 2009;96:1114

2. Lieberman ME, Levitt MA: Spontaneous rupture of the spleen: a case report and literature review. Am J Emerg Med, 1989; 7(1): 28-31

3. Pringle SD, McCartney AC, Cobbe SM. Spontaneous splenic rupture as complication of infective endocarditis. Int J Cardiol 1988;19:384-6.

4. Gananadha S, Leibman S. Spontaneous splenic rupture in a patient with bacterial endocarditis. J Am Coll Surg 2006;203:127.

5. McDonald JR, Olaison L, Anderson DJ, Hoen B, Miro JM, Eykyn S, Abrutyn S, Fowler Jr VJ, Habib G, Selton-Suty C, Pappas PA, Cabell CH, Corey GR, MarcoF, Sexton DJ. Enterococcal endocarditis: 107 cases from the international collaboration on endocarditis merged database. Am J Med 2005;118:759-66. 